$\mathrm{BFJ}$

110,8

790

\title{
Older people's perceptions towards conventional and functional yoghurts through the repertory grid method
} A cross-country study

\author{
Federico Messina, Anna Saba and Aida Turrini \\ National Institute of Research on Food and Nutrition, Rome, Italy \\ Monique Raats and Margaret Lumbers \\ Consumer Behaviour and Health Research Centre, University of Surrey, \\ Guildford, UK, and \\ Food in Later Life Team
}

\begin{abstract}
Purpose - The aim of this study is to investigate older people's perceptions, across eight European countries (the UK, Denmark, Germany, Poland, Portugal, Spain, Sweden and Italy), towards functional foods.

Design/methodology/approach - The repertory grid method was used to elicit reasons underlying preferences of five yoghurts with different functional properties and two conventional ones.

Findings - Familiarity was the key driver in products' separation. For the Italian case, as well as the Spanish, Portuguese, Danish and Swedish the first principal axis could be interpreted as novel-common axis, whilst it was not in the UK, Germany and Poland.

Research limitations/implications - Behavioural intention to buy functional yoghurts was more strongly predicted and moderated by single item perceived need (PN) than single item affective and/or cognitive attitude (AA, CA), even though PN, AA and CA could be consistently assessed within the same latent measure (in all countries but Denmark). Nevertheless, beliefs/attitudes towards a novel category of products such as functional foods may be reasonably keeping moving.

Originality/value - In this study, preference instructions pertaining to beneficial and imagery attributes, revealed idiosyncratic properties associated with functional yoghurts across eight European samples of older people.
\end{abstract}

Keywords Elderly people, Older consumers, Dairy products, Consumer behaviour, Brands, Europe

Paper type Research paper

The whole Food in Later Life Project Team, coordinated by Monique Raats and Margaret Lumbers, comprises research scientists, interviewers, technicians, administrative staff, and managers who continue to make the study possible. This study has been carried out with financial support from the Commission of the European Communities, specific RTD programme "Quality of Life and Management of Living Resources", QLK1-2002-0244 7, "Choosing foods, eating meals: sustaining independence and quality of life in old age". It does not necessarily reflect its views and in no way anticipates the Commission's future policy in this area.

The authors are grateful to all the older people who took part and the cooperation of the organisations that enabled them to recruit participants. 


\section{Introduction}

The term aging conveys changes in general, development and maturation, and decline (Vaillant and Mukamal, 2001). From a biological point-of-view, ageing can be viewed as being a continuous process (Shock, 1977; Merry and Phillips, 1981) with changes to body composition (Hall et al., 1931) and reduced sensory acuity (Murphy et al., 2002). Significant reductions in a range of biological functions and parameters have been shown to occur in people over 65 years (Lanzola et al., 1991). Further on, sensory functioning was found a strong late-life predictor of individual differences in intellectual functioning (Lindenberger and Baltes, 1994). Progressive loss of body function and physical activity together with cognitive decline may have a negative impact on the social life of older people leading to a loss of independence and health-related quality of life (Keller, 2004). In that context, the relationships between ageing and nutrition include a wide range of issues: nutrition influences ageing as well as ageing influences nutrition through the changes in the physiological functions (e.g. reaction to sensorial stimuli smell, taste, thirst) and attitudes (e.g. motivations, habits).

A food can be regarded as "functional" (Ashwell, 2002) if it is satisfactorily demonstrated to affect beneficially one or more target functions in the body, beyond adequate nutritional effects, in a way that is relevant to either an improved state of health and well-being and/or reduction of risk of disease. Functional foods must remain foods, and they must demonstrate their effects in amounts that can normally be expected to be consumed in the diet. They are not pills or capsules, but part of a normal food pattern.

An understanding of the determinants of consumer acceptance of functional foods is necessary to fully exploit market opportunities (Grunert et al., 2000; Weststrate et al., 2002; van Kleef et al., 2002). Consumer research has so far mainly focused on consumer beliefs and attitudes of the functional food consumer. Several dimensions were found to describe consumers' attitudes towards functional foods: healthiness, taste, pleasure, security and familiarity (Urala and Lahteenmaki, 2004; Urala et al., 2003; Poulsen, 1999). Studies confirmed the importance of 'knowledge' when choosing functional foods (Verbeke, 2005), but socio-demographic factors were also found to be important determinants. Price and lack of information are often quoted as barriers to purchasing functional foods. Many consumers are concerned that the functional food concept could be used as a marketing ploy to justify higher prices. Acceptance appears to depend on the perceived convenience, naturalness, expected health effects and the price/benefit ratio (von Alvensleben, 2001). Respondents of one study in Denmark (Poulsen, 1999) believed that functional foods provided convenience by enriching the daily diet. This convenience may be perceived as promoting an 'easy way' of healthy living. However, consumers also perceived unnaturalness and uneasiness toward taste changes, higher prices, doubt about the enrichment effect, enrichment dosage questions, and uncertainty toward eating functional food products. On the other hand, attitudes were seen to be more positive toward the tangible aspects of functional foods. Some of these aspects, included enrichment with supplements of calcium and vitamins (Poulsen, 1999). Some studies in the USA (IFIC, 2000), indicated that older consumers (aged over 55 years) were using functional foods to target a specific health concern more frequently than younger people, showing so a positive inclination towards functional foods (Gilbert, 1997; Poulsen, 1999). Americans, aged 55 years and older, were found most likely to be eating specific foods or components for a specified health
Perceptions towards yoghurts

791 
BFJ

110,8

792 condition (IFIC, 2005). In Denmark, a study revealed that the elderly and females were more interested in purchasing functional foods with the elderly more willing to pay higher prices given a food's positive health effects (Poulsen, 1999). Older men were more likely than younger men to take supplemental vitamin $\mathrm{E}$ and $\mathrm{A}$, but among women, use of these supplements was similar regardless of age (Lyle et al., 1998). The prolonged intake of natural functional foods may help to slow down the rate of degenerative changes (Shatenstein et al., 2003). In some populations, longevity has been associated with foods containing Lactobacillus bulgaricus (Metchnikoff, 1907). A good diet during old age has been shown to improve physiological and cognitive function, as well as the immune response (Barberger-Gateau et al., 2005; Ravaglia et al., 2005). Functional foods consumption can be an effective approach to strengthen the immune defences (always within a balanced dietary pattern) also because the desired results can be attained without going through the struggle of persuading people to change the overall composition of their diets (Holm, 2003). As an example, Lactobacillus Casei DN-114 resulted to be effective in decreasing the number and the duration of winter infections (often lethal for older people) (Turchet et al., 2003; Parra et al., 2004). Menrad (2003) has reported an increasing trend towards the consumption of functional foods (mainly yoghurts) in European countries although 75 per cent of functional products are likely to be withdrawn from the market because sales do not achieve the expected level.

Given the demographic changes in European countries resulting in an ageing population, older consumers reflect an important market segment and are worthwhile of further study (Leventhal, 1997) in order to determine their food-related needs and preferences to enhance overall quality of life (Barr and Schumacher, 2003). Healthy ageing is characterised by the consumption of a high-quality diet, as well as non-smoking and physical activity (Haveman-Nies et al., 2003). As there is little evidence of dietary change in older people (Frewer et al., 2003) one might expect that functional foods might provide an alternative way to incorporate health-giving nutrients in the diet whilst not having to fundamentally change the diet. So whilst older consumers may be relatively interested in functional foods, consumer attitudes regarding the acceptability of functional foods remain mixed and susceptible to individual differences (Poulsen, 1999).

The aim of the present study was to investigate older people's perceptions, across eight European countries, towards functional foods. Motives/reasons underlying preferences of yoghurts were emphasized in order to get most idiosyncratic cultural differences, especially the North Western (the UK, Denmark, Sweden, Germany, Poland) versus the South Western Europe (Italy, Spain, Portugal).

\section{Methodology}

Subjects

In each of eight European countries, United Kingdom, Italy, Denmark, Germany, Poland, Portugal, Spain and Sweden, the sample comprised 96 individuals partitioned into eight groups, according to three variables of classification:

(1) gender (male/female);

(2) age (65-74/75 + ); and

(3) living circumstances (alone/with others). 
Overall, participants were $768(96 \times 8)$, mean age was 74.38 ( \pm s.d. $=5.87)$, actually only 4 per cent were over 85 -years-old.

People were recruited by word-of-mouth. A snowball method was applied: each interviewee was asked to recommend other people they know and who might be interested in the project.

Perceptions towards yoghurts

\section{Interviews}

The repertory grid method (RGM) (Kelly, 1955), a simple and easy way to collect information from people (Thomson and McEwan, 1988; Russell and Cox, 2004), was used to compare older people's beliefs and perceptions about functional foods across cultures, age groups and living circumstances.

In each country seven types of yoghurts were selected: a plain and a fruit probiotic yoghurts, a yoghurt with a cholesterol lowering component, a low fat yoghurt, a vitamin enriched yoghurt, and two conventional yoghurts one with fruit and one plain.

Each participant was presented with three triads so that all seven yoghurts were included at least once. Empty packages or photographs of the selected products were shown to the participants, brand of the products was shown. For each triad, respondents were asked to rank the products in order of preference, from the most likely choice to the least likely choice. Then the interviewer asked the participant: "Why did you choose ' 1 ' instead of ' 2 ' as your most likely choice?" and "Why did you choose ' 3 ' instead of ' 2 ' as your least likely choice?" The interviewer probed for "anything else" until respondent had nothing else to say. This approach was used across all eight countries to elicit both positive and negative constructs related to their choices. Last, participants were shown their own list of elicited constructs and asked to rate all products on all constructs on a continuum scale from 1 (not at all), 2 (slightly), 3 (moderately), 4 (very) to 5 (extremely). When the participant was unable to score, a zero was recorded. Thus, a matrix of ratings was obtained for every participant who had assessed all seven yoghurts for a given set of constructs.

Following the data collection, the constructs were translated into English. The content analysis of constructs elicited by participants in all eight countries was undertaken by two authors. At first, each independently grouped the constructs into categories using a predetermined category system. When disagreements occurred, the classification system was discussed until agreement was reached. Then a further revision involving all 8 countries took place to ensure that all the constructs were interpreted and classified correctly. The resulting lists of categories were translated into English. To ensure that the same conceptual understanding was behind the coding of all data sets and to check for linguistic errors, all allocated codes were finally checked and synchronized across countries by one single researcher. Finally, a subsequent analysis of the constructs lead to the elimination of some categories (especially those redundant) and to the final categories. Thus, all countries were involved in reviewing both corrections and categorization in order to achieve a common classification criteria and all elicited constructs were put into a list of more general categories through discussion and examining the poles of each concept. When a respondent reported more than one of the same (recoded) construct the average score of these was used (Delahunty et al., 1997). 
$\mathrm{BFJ}$

110,8

794
Attitude towards functional food

The questionnaire included some components from the Theory of Planned Behaviour (TPB) (Ajzen, 1991), a model of attitude-behaviour relationships which comprises several interrelated components: attitudes, perceptions of social pressure, perceived behavioural control (person's self-confidence in the ability to form behavioural intention), intention to perform the behaviour. A component measuring the extent to which it is felt a need to eat functional foods (perceived need) was assessed as well (Payne et al., 2004). Individuals were asked to respond, using five-point Likert scales, single item questions about their affective attitude, referring to emotions and drives engendered by the prospect of performing a behaviour ("How unenjoyable or enjoyable would it be for you to buy foods with added health benefits in the next month?", ranging from 1 , extremely unenjoyable, to 5 , extremely enjoyable), cognitive attitude, a more cognitive consideration of the extent to which performing a behaviour would be advantageous, ("How harmful or beneficial would it be for you to buy foods with added health benefits in the next month?", ranging from 1, extremely harmful, to 5, extremely beneficial), perceived need ("To what extent do you feel that you need to bay foods with added health benefits in the next month?", ranging from 1,/definitely do not, to 5,7 definitely do) and behavioural intention ("To what extent do you intend to buy foods with added health benefits in the next month?", ranging from 1 , I definitely do not intend, to 5, I definitely intend).

\section{Data analysis}

Generalized Procrustes Analysis (GPA) (Gower, 1975; Arnold and Williams, 1986) was employed to analyse RGM data. This is a powerful statistical tool that can be used to derive a perceptual map (configuration, i.e. principal components plot) of a range of objects from individual sets of data of any number of people. Procrustes analysis originated as a method for matching two multidimensional configurations (Hurley and Cattell, 1962). The sum of the squared distances (Euclidean distances) between the two adjusted configurations is known as the Procrustes statistic and is a measure of their closeness. The mathematical operations of translation to a common origin, rotation/reflection of axes and dilation (stretching and shrinking) are used to make one configuration approach the other as closely as possible (McEwan and Hallett, 1990). For GPA, an extension of the original method, a consensus, or average, configuration represents the main perceptual dimensions common to all individuals, maximizing the similarities amongst them. The technique allows the relative importance of each individual's constructs to be evaluated. The consensus configuration provides a valuable summary of how the individuals view the relationships between the products on the average but the configuration certainly does not represent a consensus of views, rather it represents an average that may conceal a wide range of differences of viewpoints (Dijksterhuis and Gower, 1991). The characteristic of GPA is that it performs a symmetric analysis, this means that each individual matrix has seven products/rows for the same number of constructs/columns, displaying zeros' column when a construct is not elicited by the respondent.

Interpretation of the dimensions in the resulting low-dimensional consensus configuration is based on average correlations (loading coefficients) between the original constructs and the extracted principal components. The most important 
constructs were identified as those with loading coefficient equal to \pm 0.3 or greater (Thomson and McEwan, 1988). The analysis of the Repertory Grid Method data using GPA was carried out using statistical software Genstat (Genstat, 2003), whereas mean values together with internal consistency reliability, Cronbach's a (Kline, 2005), and stepwise regression of behavioural intention to buy on attitudes as well as perceived need were assessed using SPSS version 12.0 (SPSS, 2003).

\section{Results}

A total of 56 distinct constructs' categories representing motives of choice as well as similarity and/or preference judgements were elicited across countries. Examining the amount of constructs, on average, over ten reasons were mentioned per Spanish participant, seven per British and Swedish, six per Italian, and between three and four per German, Danish, Polish. Portuguese respondents provided a mean of attributes under three (Table I). Higher number of constructs could imply more complex cognitive structures with regard to the products. Moreover, there is also a possibility that such differences in response complexity could be attributed to an interviewer effect. In this study, however, we believe to have minimized any such effect by thorough training of all interviewers and by using multiple interviewers in each country.

Some categories were more or less frequently common across all countries. Actually, these were familiar with product, I like taste, natural product, trust, health benefits - general, health benefits - specific, I like appearance of product/packaging, convenience of product, nutritional content.

GPA consensus plots were depicted in Figure 1 for the 96 older people of the UK, Denmark, Germany, Sweden respectively and in Figure 2 for Italy, Spain, Portugal and Poland. GPA yielded multi-dimensional representations of the seven products for each country, where constructs more highly correlated (loading coefficient $= \pm 0.3$ or greater) with the principal axes (PAs) were in bold font (other constructs in italic font were mentioned by over 20 individuals but weakly correlated).

In Figure 1 peculiar reasons for choice associated with the two conventional (fruit creamy and plain creamy) yoghurts were familiar with product, I like taste, I like consistency/texture as well as/like flavour and portion size. The other five products were clearly separated and described by constructs such as health benefits - general, fat content - low, I like appearance of product and it contains additives (this latter in Germany).

In Figure 2 three Southern countries such as Italy, Spain and Portugal emphasised what found out in the Northern ones, in fact the two conventional (fruit creamy and

\begin{tabular}{lcc}
\hline Country & Average number of constructs per interviewee & Number of constructs' categories \\
\hline Portugal & 3 & 30 \\
Poland & 3 & 25 \\
Denmark & 3 & 34 \\
Germany & 4 & 31 \\
Italy & 6 & 40 \\
Sweden & 7 & 45 \\
UK & 7 & 43 \\
Spain & 11 & 32
\end{tabular}

\section{Perceptions towards yoghurts}

795 
BFJ

110,8

796

Figure 1.

GPA consensus plots (UK, Denmark, Germany, Sweden)
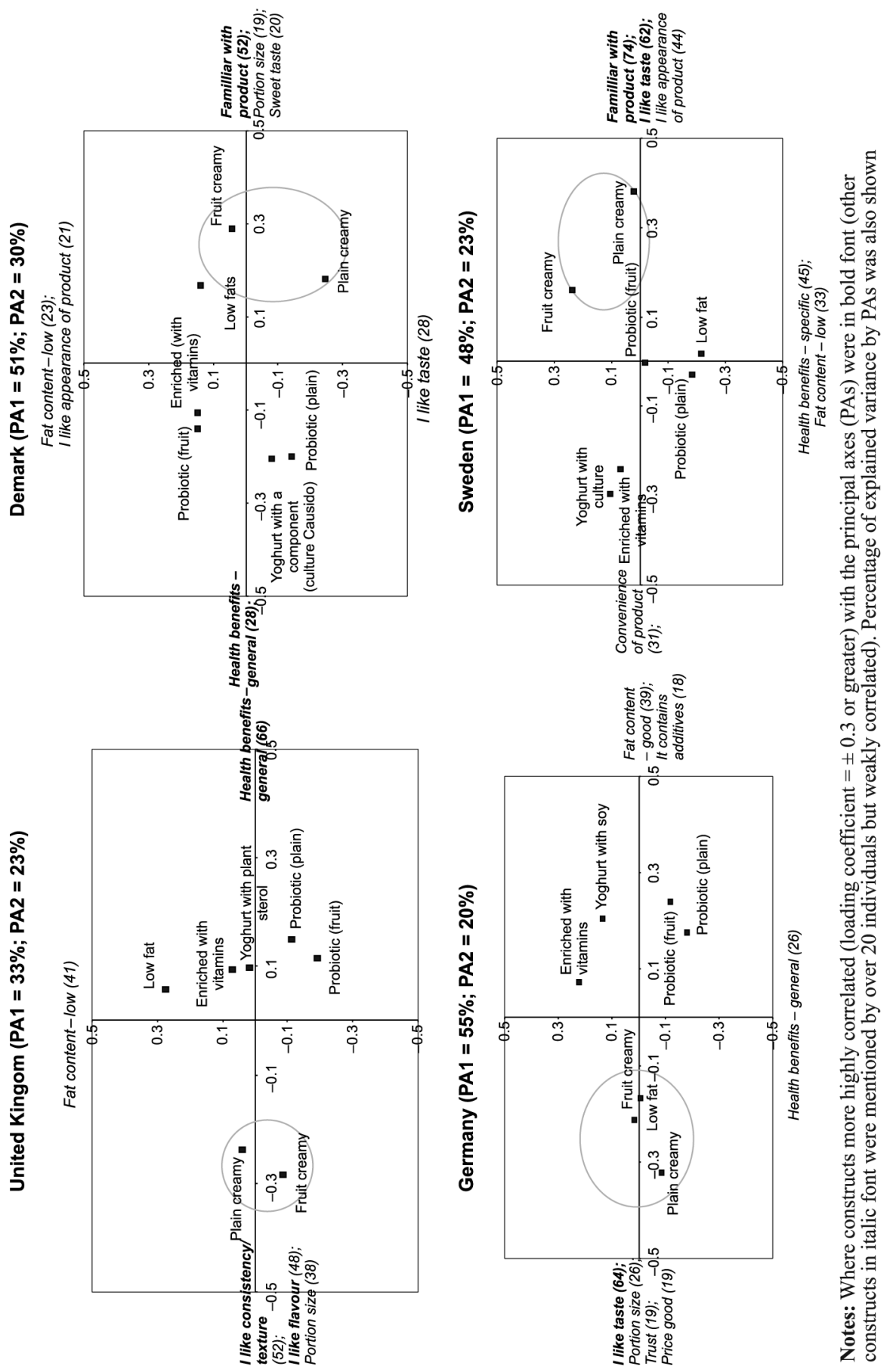

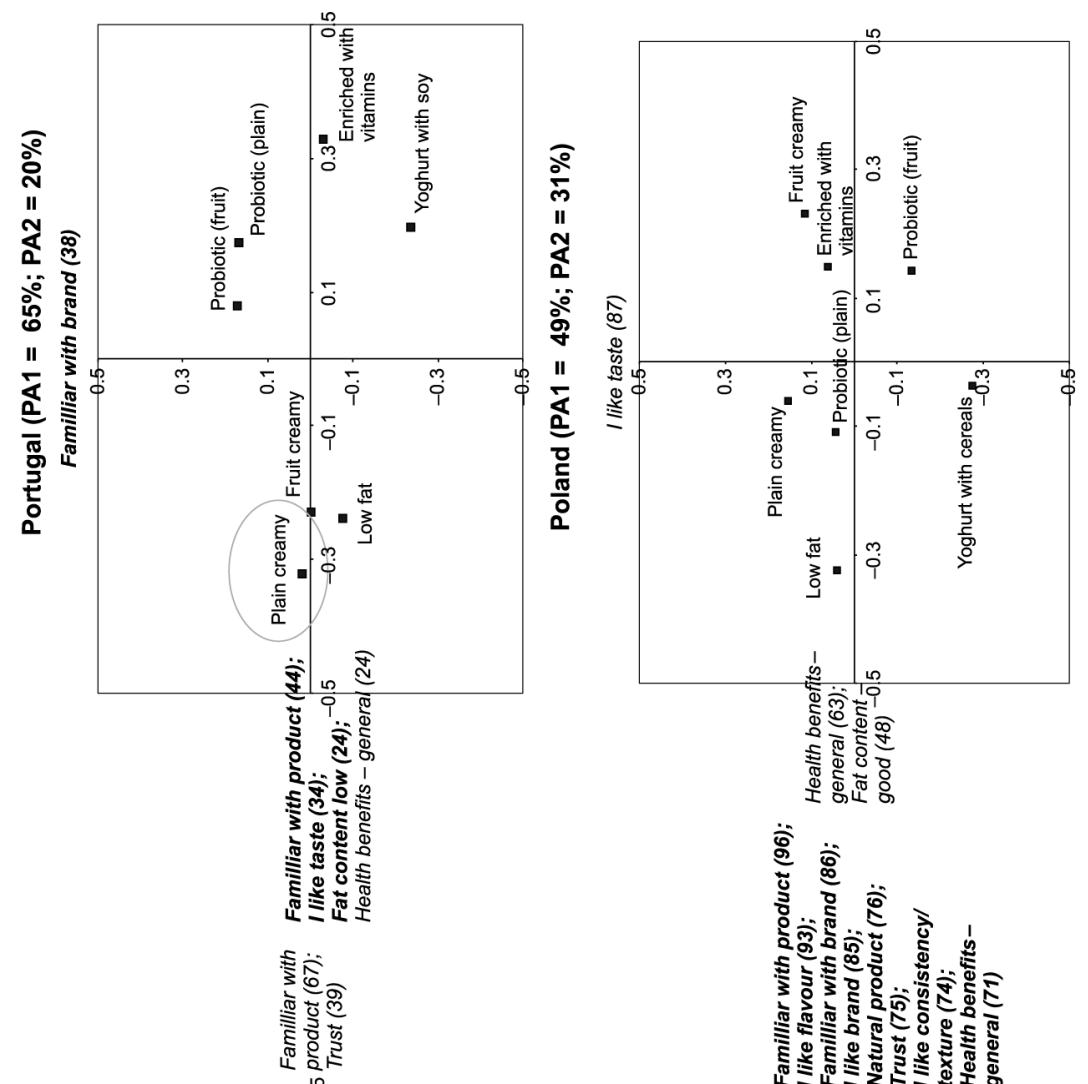

Perceptions towards yoghurts
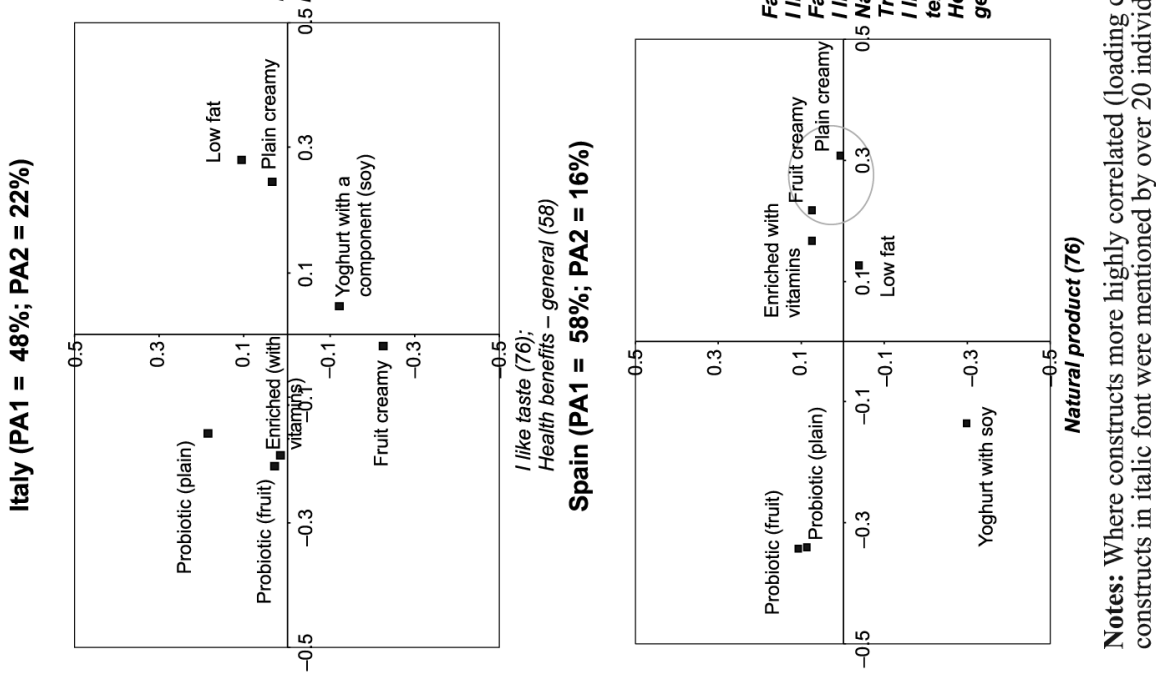

Figure 2. GPA consensus plots (Italy, Portugal, Spain, Poland) 
$\mathrm{BFJ}$

110,8

798 plain creamy) yoghurts reflected preference judgements about familiarity and/like taste, trust, whereas the functional products were more scattered around. In particular for Italy the one with low fat was close to the plain yoghurt, while at the same the one with a component (soy) was near the fruity conventional one. For Spain and Portugal the low fat yoghurt was perceived in the same way as the two conventional yoghurts. Poland described above all the low fat yoghurt for health benefits - general and fat content-good. That plain one was associated with/like taste.

It is interesting to point out that two types of reasons underlying product preferences were one related to the product knowledge, familiar with product/brand, the other one to a sensory meaning (like taste/flavour/consistency/texture). "Familiarity" was more related to Southern countries ("brand" was particularly important for Spain and Portugal) as well as Sweden whilst it was not meaningful in UK, Germany and Poland. The more the products were familiar the more they were recognized through beneficial and imagery attributes. In Northern countries (Figure 1) the most important constructs older people associated with functional yoghurts were related to health benefits, where two dimensions were evidenced one health-related and one sensory-related.

Older people were also asked to evaluate their propensity to approach or avoid these novel foods measuring their perceived need of buying them (PN), their attitude (affective, AA, and cognitive, CA) and their intention to buy (BI) (Table II). Mean scores were shown ranked according to the average PN. Danish older people had the floor PN value (1.89) as well as the two components of attitude (respectively $\mathrm{AA}=2.68$ and $\mathrm{CA}=3.08$ ) and the lowest intention (2.29). Similarly, Germany, Sweden and the UK gave evidence of a mean PN less than three, this central point could be interpreted as a threshold assessing a first perception of need. The Southern countries (Portugal, Italy and Spain) together with Poland had a PN over three and also higher scores for BI and AA, CA as well. Our findings showed that although older people may have a positive
attitude towards a behaviour (such as, for instance, CA for Germany, Sweden and UK), AA, CA as well. Our findings showed that although older people may have a positive
attitude towards a behaviour (such as, for instance, CA for Germany, Sweden and UK),

\begin{tabular}{lcccc}
\hline Country & PN & AA & CA & BI \\
\hline DEN & 1.89 & 2.68 & 3.08 & 2.29 \\
& $(0.99)$ & $(1.14)$ & $(0.76)$ & $(1.27)$ \\
GER & 2.36 & 3.29 & 3.38 & 2.85 \\
& $(0.91)$ & $(1.02)$ & $(0.73)$ & $(1.20)$ \\
SWE & 2.56 & 3.48 & 3.37 & 3.01 \\
& $(1.00)$ & $(0.90)$ & $(0.73)$ & $(0.84)$ \\
UK & 2.92 & 3.37 & 3.58 & $(1.39)$ \\
& $(1.31)$ & $(0.74)$ & $(0.62)$ & 3.32 \\
POR & 3.00 & 3.58 & 3.98 & $(1.77)$ \\
& $(1.78$ & $(1.36)$ & $(0.85)$ & 3.13 \\
ITA & 3.16 & 3.47 & 3.43 & $(1.21)$ \\
& $(1.17)$ & $(1.14)$ & $(0.89)$ & $(1.62$ \\
SPA & 3.64 & 3.27 & 3.53 & 3.92 \\
& $(1.43)$ & $(1.08)$ & $(0.58)$ & $(1.41)$ \\
POL & 3.65 & 3.81 & 3.94 & $(1.17$ \\
& $(1.40)$ & $(0.87)$ & $(0.81)$ & $(.40)$ \\
Average & 2.90 & 3.37 & $(0.80)$ & \\
& $(1.40)$ & $(1.09)$ & &
\end{tabular}

Table II.

Mean scores (between brackets standard deviation) of perceived need (PN), affective and cognitive attitudes (AA, CA) as well as behavioural intention (BI) towards functional foods 
this does not necessarily mean he/she feels a need to carry out the behaviour (Paisley and Sparks, 1998). Actually, in these countries, PN was respectively 2.36, 2.56 and 2.92. On the other hand, in Portugal, Italy and Spain the two components, CA and PN, appeared in the same direction and in Spain PN (3.64) even exceeded CA (3.53). Spain and Poland also had positive behavioural intention (3.63 and 3.92 respectively).

It was noteworthy that the three items, AA, CA, PN, could be consistently assessed within the same latent measure, as a matter of fact Cronbach's coefficients (a) reported values from 0.64 (UK), 0.73 (Poland and Spain), 0.75 (Portugal), 0.78 (Germany), 0.79 (Sweden), 0.82 (Italy), therefore, reliability scores revealed adequate/good homogeneity between the items (Kline, 2005). On the other hand, Denmark obtained a weak score of reliability (0.55), actually if PN deleted AA and CA were adequately consistent between each other (0.67). Nevertheless, stepwise regression for behavioural intention (BI) on $\mathrm{AA}, \mathrm{CA}$ and $\mathrm{PN}$ (Table III) revealed that PN was stronger than $\mathrm{AA}$ and $\mathrm{CA}$ in explaining BI across countries. Only in Denmark AA was the first regressor to enter. Spain got the ceiling value of $R^{2}=0.77$ and the floor one was for Sweden (0.42).

The three items all together were significant explanatory for BI only in the case of the UK as well as Germany and Denmark. Basically, the comparison of unstandardized regression coefficients emphasized that behavioural intention was more strongly predicted and moderated by perceived need than affective and/or cognitive attitude.

\section{Discussion}

Differences in perceptions and therefore in preferences were found for functional and conventional yoghurts, highlighting interesting cultural differences for older people across countries. The more frequent and common attributes discriminating functional and conventional yoghurts were knowledge and familiarity with products. Taste (seven like taste) was one of the most important factors determining preference,

\begin{tabular}{|c|c|c|c|c|}
\hline & \multicolumn{3}{|c|}{ Variables entered unstandardized coefficients } & \multirow{2}{*}{$\begin{array}{l}\text { Goodness of fit } \\
\text { Adjusted } R^{2}\end{array}$} \\
\hline & I & II & III & \\
\hline \multirow[t]{2}{*}{ UK } & $\mathrm{PN}$ & $\mathrm{CA}$ & $\mathrm{AA}$ & \multirow[t]{2}{*}{0.64} \\
\hline & 0.66 & 0.42 & 0.25 & \\
\hline \multirow[t]{2}{*}{ ITA } & PN & $\mathrm{AA}$ & - & \multirow[t]{2}{*}{0.60} \\
\hline & 0.62 & 0.27 & - & \\
\hline \multirow[t]{2}{*}{ GER } & $\mathrm{PN}$ & $\mathrm{CA}$ & $\mathrm{AA}$ & \multirow[t]{2}{*}{0.55} \\
\hline & 0.58 & 0.42 & 0.23 & \\
\hline \multirow[t]{2}{*}{ SWE } & $\mathrm{PN}$ & $\mathrm{CA}$ & - & \multirow[t]{2}{*}{0.42} \\
\hline & 0.37 & 0.34 & - & \\
\hline \multirow[t]{2}{*}{ DEN } & $\mathrm{AA}$ & $\mathrm{PN}$ & CA & \multirow[t]{2}{*}{0.49} \\
\hline & 0.44 & 0.42 & 0.37 & \\
\hline \multirow[t]{2}{*}{ FOR } & $\mathrm{PN}$ & $\mathrm{AA}$ & - & \multirow[t]{2}{*}{0.60} \\
\hline & 0.52 & 0.45 & - & \\
\hline \multirow[t]{2}{*}{$\mathrm{POL}$} & PN & $\mathrm{AA}$ & - & \multirow[t]{2}{*}{0.67} \\
\hline & 0.68 & 0.39 & - & \\
\hline \multirow[t]{2}{*}{ SPA } & PN & $\mathrm{AA}$ & - & \multirow[t]{2}{*}{0.77} \\
\hline & 0.69 & 0.34 & - & \\
\hline
\end{tabular}

Note: Unstandardized coefficients were statistical significant at $p<0.05$

\section{Perceptions towards yoghurts}

799
Table III.

Stepwise regression of behavioural intention $(\mathrm{BI})$ on affective attitude (AA), cognitive attitude (CA), perceived need (PN) 
$\mathrm{BFJ}$

110,8

800 confirming earlier results (Urala and Lahteenmaki, 2003, 2004). In the specific case of functional foods, taste was reported as a strong influential variable (Poulsen, 1999).

Generally speaking, in the present study reasons underlying older consumers' product preferences were oriented towards familiarity with product/brand (best associated with the two conventional yoghurts) and good taste/flavour. Functional yoghurts were described by similarity (objective) judgements (for instance fat content - low related to a low fat product as well as health benefits for a probiotic one), therefore consumers expressed their perception based on characteristic attributes as reported by previous research (Lefkoff-Hagius and Mason, 1993). Familiarity was the key driver in products' separation, actually for the Italian case, as well as the Spanish, Portuguese, Danish and Swedish the first principal axis could be interpreted as novel-common axis (Jaeger et al., 2005). Our findings confirmed other works (Tuorila et al., 1998; Arvola et al., 1999) regarding to lower expectations for unfamiliar products, the more the products were familiar the more they were recognized through beneficial and imagery attributes (Creusen and Schoormans, 1997). The functional yoghurts (e.g. probiotic yoghurts and vitamin enriched yoghurts) even though they always distinguished, were perceived in a vague and uncertain manner and it was not easy to associate peculiar attributes of characterisation and discrimination to them. Preference instructions, pertaining to beneficial and imagery attributes, revealed more idiosyncratic properties (Derbaix and Sjoberg, 1994) and in our study it was inferred that the two "probiotic" yoghurts and the cholesterol lowering yoghurt were described as containing additives by German seniors; similarly, other countries didn't associate these yoghurts with abstract judgements of preference such as/like taste or trust. One reason for these results might be that functional yoghurts are more processed and therefore perceived as being somewhat less natural (Jonas and Beckman, 1998; Poulsen, 1999; Cox et al., 2004).

It is noteworthy that in other studies self-reported consumer knowledge has a negative impact on the likelihood to accept functional food (Verbeke, 2005), even though fading away with increasing age. All the over 65-years-old consumers gave evidence of positive attitude towards these products across countries. However, perceived need of functional foods resulted very poor especially in Denmark, Germany, Sweden and the UK. Consequently, behavioural intention to buy was more strongly predicted and moderated by perceived need than affective and/or cognitive attitude.

As long as a rewarding feeling connected to the use of functional foods is acknowledged, particularly by middle aged and older people because of their awareness of health issues (Verbeke, 2005), food companies' efforts should concentrate on the appropriate way of satisfying consumers' expectations/preferences of high-quality food product (with high sensory properties as well). It is much easier to gain people acceptance for a product enriched with more familiar ingredients, such as vitamin C, calcium, omega-3, than it is for unfamiliar ones, such as selenium (Bech-Larsen and Scholderer, 2007). The assumption that functional foods with specific ingredients are likely to deliver health benefits is now generally accepted (Diplock et al., 1999; Mermelstein, 2002), and probiotics have been shown to have a significant potential for improving human health and preventing and treating disease (Goldin, 1998).

A critical point with respect to how functional foods may influence public health is the fact that the marketing of functional foods links individual food products to specific 
health benefits. In this way, the focus on the role of single products for health could draw the (specifically older) consumers' attention away from the diet as a whole (Holm, 2003).

Finally, functional foods might promote a way of thinking of food and health that is in conflict with well-established practical ways of ensuring a balanced diet. In order to be marketed, functional foods are associated with claims about their nutrient composition and about health benefit they may provide (Heasman and Melletin, 2001). On the one hand, food industries, food retailers and public authorities have to strengthen efforts to inform targets of populations about overall dietary balance in order to compensate for the single-food health information. On the other hand, public authorities have to regulate health claims on specific products to ensure that the information is communicated clearly and honestly to consumers.

\section{Conclusion}

Further research is needed to assess older consumers' willingness to buy functional foods in rational/cognitive oriented decision-making process, because positive attitude affects subsequent behaviour. This study evinced that familiarity was the key driver in functional versus conventional yoghurts' choice. Because people's perception become more stable when the products are more familiar (Eagly and Chaiken, 1993) beliefs and attitudes towards a novel category of products such as functional foods may be reasonably keeping moving.

\section{References}

Ajzen, I. (1991), "The theory of planned behaviour", Organizational Behavior and Human Decision Processes, Vol. 50, pp. 179-211.

Arnold, G.M. and Williams, A.A. (1986), "The use of generalised procrustes techniques in sensory analysis", in Piggott, J.R. (Ed.), Statistical Procedures in Food Research, Elsevier Applied Science, London.

Arvola, A., Lahteenmaki, L. and Tuorila, H. (1999), "Predicting the intent to purchase unfamiliar and familiar cheeses: the effect of attitudes, expected liking and food neophobia”, Appetite, Vol. 32, pp. 113-26.

Ashwell, M. (2002), Concepts of Functional Foods, Europe Concise Monograph Series, International Life Sciences Institute (ILSI), Washington, DC.

Barberger-Gateau, P. and Berr, C. (2005), "Nutrition and risk of dementia: data from the epidemiological studies PAQUID and EVA", in Barberger, P. and Berr, C. (Eds), Nutrition Cognitive Decline and Aging, Nutrition Cognitive Decline and Aging, Serdi Publisher, Paris, pp. 12-20.

Barr, J.T. and Schumacher, G.E. (2003), "The need for a nutrition-related quality-of-life measure”, Journal of American Dietetic Association, Vol. 103 No. 2, pp. 177-80.

Bech-Larsen, T. and Scholderer, J. (2007), "Functional foods in Europe: consumer research, market experiences and regulatory aspects", Trends in Food Science \& Technology, Vol. 18, pp. 231-4.

Cox, D.N., Koster, A. and Russell, C.G. (2004), "Predicting intentions to consume functional foods and supplements to offset memory loss using an adaptation of protection motivation theory", Appetite, Vol. 43, pp. 55-64.

\section{Perceptions towards yoghurts}

801 
$\mathrm{BFJ}$

110,8

802

Creusen, M.E.H. and Schoormans, J.P.L. (1997), “The nature of differences between similarity and preference judgements: a replication with extension”, International Journal of Research in Marketing, Vol. 14, pp. 81-7.

Delahunty, C., McCord, A., O’Neill, E. and Morrissey, P. (1997), "Sensory characterisation of cooked hams by untrained consumers using free-choice profiling", Food Quality and Preference, Vol. 8 Nos 5/6, pp. 381-8.

Derbaix, C. and Sjoberg, L. (1994), "Movie stars in space: a comparison of preference and similarity judgements", International Jaurnal of Research in Marketing, Vol. 11, pp. 261-74.

Dijksterhuis, G.B. and Gower, J.C. (1991), "The interpretation of generalized procrustes analysis and allied methods", Food Quality and Preference, Vol. 3, pp. 67-87.

Diplock, A.T., Aggett, P.J., Ashwell, M., Hornet, F., Fern, E.B. and Roberfroid, M. (1999), "Scientific concepts of functional foods in Europe: consensus document", British Journal of Nutrition, Vol. 81 No. 4, pp. S1-S27.

Eagly, A.H. and Chaiken, S. (1993), The Psychology of Attitudes, Hartcourt Brace Jovanovich College Publisher, Orlando, FL.

Frewer, L., Scholderer, J. and Lambert, N. (2003), "Consumer acceptance of functional foods: issues for the future", British Food Journal, Vol. 10, pp. 714-31.

Genstat (2003), Genstat 7th Edition, VSN International Ltd, Oxford.

Gilbert, L. (1997), "The consumer market for functional foods", Journal of Nutraceuticals, Functional and Medical Foods, Vol. 1 No. 3, pp. 5-21.

Goldin, B.R. (1998), "Health benefits of probiotics", British Journal of Nutrition, Vol. 80, pp. S203-7.

Gower, J.C. (1975), “Generalized procrustes analysis”, Psychometrika, Vol. 40, pp. 33-51.

Grunert, K.G., Bech-Larsen, T. and Bredhal, L. (2000), "Three issues in consumer quality perception and acceptance of dairy products", International Dairy Journal, Vol. 10, pp. 575-84.

Hall, D.A., Blackett, A.D. and Zajac, A.R. (1931), "Changes in skin-fold thickness with increasing age", Age and Ageing, Vol. 10, p. 19.

Haveman-Nies, A., De Groot, L.C.P.G.M. and Van Staveren, W.A. (2003), "Dietary quality, lifestyle factors and healthy ageing in Europe: the SENECA study", Age and Ageing, Vol. 32, pp. 427-34.

Heasman, M. and Melletin, J. (2001), The Functional Foods Revolution: Healthy People, Healthy Profit, Earthscan Publications, London.

Holm, L. (2003), "Food health policies and ethics: lay perspectives on functional foods", Journal of Agricultural and Environmental Ethics, Vol. 16, pp. 531-44.

Hurley, J.R. and Cattell, R.B. (1962), "The Procrustes program: producing direct rotation to test a hypothesised factor structure", Behavioural Science, Vol. 7, pp. 258-62.

IFIC (2000), Foods: Attitudinal Research (1996-1999), International Food Information Council Foundation (IFIC), Washington, DC.

IFIC (2005), Consumer Attitudes Towards Functional Foods/Foods for Health, International Food Information Council Foundation (IFIC), Washington, DC.

Jaeger, S.R., Rossiter, K.L. and Lau, K. (2005), "Consumer perceptions of novel fruit and familiar fruit: a repertory grid application", Journal of the Science of Food and Agriculture, Vol. 85, pp. $480-8$.

Jonas, M.S. and Beckman, S.C. (1998), Functional Foods: Consumer Perceptions in Denmark and England, working paper 55, MAPP, Arhus. 
Keller, H.H. (2004), "Nutrition and health-related quality of life in frail older adults", The Journal of Nutrition, Health and Aging, Vol. 8 No. 4, pp. 245-52.

Kelly, G.A. (1955), The Psychology of Personal Constructs, Norton, New York, NY.

Kline, R.B. (2005), Structural Equation Modeling, The Guilford Press, New York, NY.

Lanzola, E. (1991), "Le basi conoscitive della nutrizione nell'anziano", Alimentazione $e$ comportamenti alimentari nell'anziano ricoverato, Istituto Scotti Bassani, Milano, pp. 4-20.

Lefkoff-Hagius, R. and Mason, C.H. (1993), "Characteristic, beneficial and image attributes in consumer judgements of similarity and preference", Journal of Consumer Research, Vol. 20, pp. 100-10.

Leventhal, R.C. (1997), "Aging consumers and their effects on the marketplace", Journal of Consumer Marketing, Vol. 14 No. 4, pp. 276-81.

Lindenberger, U. and Baltes, P.B. (1994), "Sensory functioning and intelligence in old age: a strong connection", Psychology and Aging, Vol. 9, pp. 339-55.

Lyle, B.J., Mares-Perlman, J.A., Klein, B.E.K., Klein, R. and Greger, J.L. (1998), "Supplement users differ from nonusers in demographic, lifestyle, dietary and health characteristics", Journal of Nutrition, Vol. 128, pp. 2355-62.

McEwan, J.A. and Hallett, E. (1990), A Guide to the Use and Interpretation of Generalised Procrustes Analysis, Technical Manual 30, CFDRA, Chipping Campden.

Menrad, K. (2003), "Market and marketing of functional foods in Europe", Journal of Food Engineering, Vol. 56, pp. 181-8.

Mermelstein, N.H. (2002), "A look into the future of food science \& technology", Food Technology, Vol. 56 No. 1, pp. 46-55.

Merry, B. and Phillips, J. (1981), "Basic gerontology", Clinics in Endocrinology and Metabolism. Endocrinology and Ageing, Saunders, London.

Metchnikoff, E. (1907), The Prolongation of Life, Heinemann, London.

Murphy, C., Schubert, C.R., Cruickshanks, K.J., Klein, B.E.K., Ronald Klein, R. and Nondahl, D.M. (2002), "Prevalence of olfactory impairment in older adults", Journal of the American Medical Association, Vol. 288, pp. 2307-12.

Paisley, C.M. and Sparks, P. (1998), "Expectations of reducing fat intake: the role of perceived need within the theory of planned behaviour", Psychology \& Health, Vol. 13, pp. 341-53.

Payne, N., Jones, F. and Harris, P.H. (2004), "The role of perceived need within the theory of planned behaviour: a comparison of exercise and healthy eating", British Journal of Health Psychology, Vol. 9, pp. 489-504.

Parra, D., Martinez de Morentin, B., Cobo, J.M., Mateos, A. and Marlines, J.A. (2004), "Monocyte function in healthy middle-aged people receiving fermented milk containing Lactobacillus casei”, The Journal of Nutrition, Health and Aging, Vol. 8 No. 4, pp. 208-11.

Poulsen, J.B. (1999), “Danish consumers' attitudes towards functional foods”, Working Paper 62, MAPP, Arhus.

Ravaglia, G., Forti, P., Maioli, F., Muscari, A., Sacchetti, L., Arnone, G., Nativio, V., Talerico, T. and Mariani, E. (2005), "Homocysteine and cognitive function in healthy elderly Italian community-dwellers", Nutrition Cognitive Decline and Aging, Serdi Publishers, Paris, pp. 49-53.

Russell, C.G. and Cox, D.N. (2004), "Understanding middle-aged consumers' perceptions of meat using repertory grid methodology", Food Quality and Preference, Vol. 15, pp. 317-29.

Shatenstein, B., Payette, H., Nadon, S., Gray-Donald, C. and Members of the Division on Nutrition and Healthy Aging, Quebec Network on Aging Research (2003), An Approach for
Perceptions towards yoghurts 
$\mathrm{BFJ}$

110,8

804
Evaluating Lifelong Intakes of Functional Foods in Elderly People, American Society for Nutritional Sciences, Bethesda, MD, pp. 2384-91.

Shock, N.W. (1977), "Systems integration", in Finch, C.E. and Hayflick, L. (Eds), Handbook of Biology and Aging, van Nostrand Reinbold, London, p. 639.

SPSS (2003), Statistical Package for Social Scientists, SPSS 12.0, Chicago, IL.

Thomson, D.M.H. and McEwan, J.A. (1988), "An application of the repertory grid method to investigate consumer perceptions of foods", Appetite, Vol. 10, pp. 181-93.

Tuorila, H., Meiselman, H., Bell, R., Cardello, A.V. and Lesher, L.L. (1998), "Effect of expectations and the definition of product category of the acceptance of unfamiliar foods", Food Quality and Preference, Vol. 9, pp. 421-30.

Turchet, P., Laurenzano, M., Auboiron, S. and Antoine, J.M. (2003), "Effect of fermented milk containing the probiotic Lactobacillus Casei DN-114 001 on winter infections in free-living elderly subjects: a randomised, controlled study", Journal of Nutrition and Aging, Vol. 7 No. 2, pp. 75-7.

Urala, N. and Lahteenmaki, L. (2003), "Reasons behind consumers' functional food choices", Nutrition \& Food Science, Vol. 33, pp. 148-58.

Urala, N. and Lahteenmaki, L. (2004), "Attitudes behind consumers' willingness to use functional foods", Food Quality and Preference, Vol. 15, pp. 793-803.

von Alvensleben, R. (2001), "Beliefs associated with food production", in Frewer, L., Risvik, E. and Schifferstein, H. (Eds), Food, People, and Society a European Perspective of Consumer's Food Choices, Springer-Verlag, Berlin, pp. 381-400.

van Kleef, E., van Trijp, C.M., Luning, P. and Jongen, W.M.F. (2002), "Consumer-oriented functional food development: how well do functional disciplines reflect the "voice of the consumer?", Trends in Food Science \& Technology, Vol. 13, pp. 93-101.

Vaillant, G. and Mukamal, K. (2001), "Successful aging”, American Journal of Psychiatry, Vol. 158 No. 6, pp. 839-47.

Verbeke, W. (2005), "Consumer acceptance of functional foods: socio-demographic, cognitive and attitudinal determinants", Food Quality and Preference, Vol. 16, pp. 45-7.

Weststrate, J.A., van Poppel, G. and Verschuren, P.M. (2002), "Functional foods, trends and future", British Journal of Nutrition, Vol. 2, Suppl. 2, pp. S233-5.

\section{Further reading}

Childs, N.M. and Poryzees, G.H. (1998), "Foods that help prevent disease: consumer attitudes and public policy implications", British Food Journal, Vol. 100 No. 9.

Urala, N. and Lahteenmaki, L. (2007), “Consumers' changing attitudes towards functional foods", Food Quality and Preference, Vol. 18, pp. 1-12.

\section{Corresponding author}

Federico Messina can be contacted at: messina@inran.it

To purchase reprints of this article please e-mail: reprints@emeraldinsight.com Or visit our web site for further details: www.emeraldinsight.com/reprints 